\title{
Performance Improvement in Steel Structures, Implementing ADAS Yielding Damper, Using Non-linear Analysis
}

\author{
Yousef Mohammadi Moghadam ${ }^{1}$, Mehrdad Movahednia ${ }^{2}$ \\ ${ }^{1}$ Department of civil Engineering, Eslamabad-E-Gharb Branch, \\ Islamic Azad University, Eslamabad-E-Gharb, Iran \\ ${ }^{2}$ Assistant professor, Department of civil Engineering, Eslamabad-E-Gharb Branch, \\ Islamic Azad University, Eslamabad-E-Gharb, Iran \\ *corresponding Author: Mehrdad_Movahednia@yahoo.com
}

\begin{abstract}
The objective of present study is to improve the performance of steel structures, Implementing ADAS yielding damper, by means of non-linear analysis. ANSYS software is utilized to model ADAS damper. 3 buildings of 5, 10 and 15 stories are studied with and without damper. Non-linear method was used to analyze. Load, displacememt, ductility, energy absorption and total strength graphs of different samples were compared. The results represent that in the 5-story structure, addition of ADAS damper leads a 3 time increment of total strength, 57\% increment of ductility and $164 \%$ increment of energy damping. In the 10-story structure, addition of ADAS damper leads a 143\% increment in total strength, a $\mathbf{2 5 \%}$ increment in ductility and $\mathbf{1 0 4 \%}$ increment of energy absorption. In 15-story structure, addition of ADAS damper leads a $24 \%$ increment in total strength, a $11 \%$ increment in ductility and a $40 \%$ increment in energy absorption. Maximum ductility is related to the model 6 with a value of 6.03 and the minimum ductility is obtained in model 1 with a value of 3.12. The maximum total strength is related to model 6, equal to 2913 tons and model 1 is related to minimum total strength of 632 tons. When comparing the energy absorption, model 1 and model 6 had the minimum and the maximum values relatively. To conclude, ADAS damper has the highest effect on short structures. The best performance of ADAS damper in comparison with the same sructure without damper is observed in 5-story buildings.
\end{abstract}

Keywords: ADAS damper, Ductility, Total strength

\section{Introduction}

During recent years, engineers have been trying to make buildings safe through increasing its strength and also aiming to keep the building in elastic zone. But this increment of strength was along with increment of stiffness which decreases the period time and magnifies the possible earthquake force. This increases the construction costs. On the other hand, the structure could not be designed for the biggest possible earthquake due to economic considerations however, prediction of the biggest earthquake characterisitics is also impossible. Thus, during big earthquakes, the structure experiences plastic zone condititions. Earthquake engineering approach, is to optimize the mechanical dynamic characteristics of the structure due to decrease the applied load and to conduct the plastic deformations to expected points of the structure. Thus, some methods were invented to increase the natural period of the structure such as implementation of seismic isolator and some methods to increase damping ratio like yielding dampers. Utilization of dampers cause ti increase the damping of the structure and conducts and concentrates the damages into forcasted points in the structure. This method does not only preserve the structure members to be damaged and make servicability available during critical conditions, but also will cause a significant save in costs and time spent for retrofitting the structure. One of these dampers which has got good energy absorption, damage conduction capacity and substitution capacity after the deterioration is metallic yielding damper.

Implementation of ADAS damper is a modern method to improve the seismic performance of structures. As the behaviors of multi-story structures require further studies, the present research studies the effect of adding ADAS damper on 5, 10 and 15-story structures' behavior.

\section{Littrature}

Various codes have declared the seismic bahavior effect of structures, by means of different parameters. Elghazouli studied the embraced structures with europian code approach [1]. Mastrandreal and Piluso studied about plastic behavior of eccenteric bracements [2]. Stability of structures is a critical problem while latteral loads are being applied to the structure frames that Gul Yigitsoy et al. have made a studied it widely [3]. Implementation of numerical and experimental relations are of methods to study the performance of bracements and frames of the structures which Yigitsoy performed some numerical researches on bracements behavior [4]. Conventional approaches to seismic design of the structures are based on ductility factor. Primary objective of sesmic design codes is to prevent structures' collapse and to lower casualities down to a safety limit. Through 
severe eartquakes, generally a vast non-linear behavior takes place in the structures in which the structures with unsufficient strength and ductility may collapse $[5,6]$. During recent decades, some studies have been performed on structure control. Active control systems are a branch of inactive bahavior control studies in the structures. Through inactive control, the applied energy damps in the structure thererfor the damages minimize. Inactive damping is categorized to different classes such as metallic dampers, friction dampers and liquid dampers. Metallic dampers are widely used by researchers [7-9]. Metallic dampers dissipate energy by pre-failure plastic deformations of the material. The advantages of these dampers are stable hysteresis behavior, low sensebility to temprature changes, high reliability and proper cost [9]. The most used energy dissipating dampers are TADAS and ADAS dampers. Thesesdampers are made up of X-shaped plates that present an out of plane bending behavior. The dimensions of such dampers are designed to have a uniform stress distribution in dampers height and all parts of the damper fail simultaneusly [10]. As the dampers dimensions are such important, recently, some studies have been performed to optimize the dimensions and performance of the damper while loading proccesses lead to fatigue [11]. Slit dampers is an innovative type of metallic dampers. These dampers are consisted of slit plates that undergo irreversible deformations. This research is about to study the performance of ADAS dampers $[12,13]$.

\section{Research method}

The structures design is performed using EATBS software. The structures are designed and sections and frames'dimensions are calculated and controlled by means of code regulations. After that the results are used for finite element method part of ANSYS software. Modelling was performed 2D, while varying the building height using ANSYS finite element software and analyzed using static non-linear method.

\section{3-1- model verification}

To make sure about the results obtained from ANSYS software, a sample of steel structure is selected from an article from Eswaramoorthi et al. [14] and is modeled and compared with experimental sample. A desirable conformation is observed between numerical and experimental results. Fig. (1) represents an acceptable accuracy in ANSYS modelling while comparing the the results.

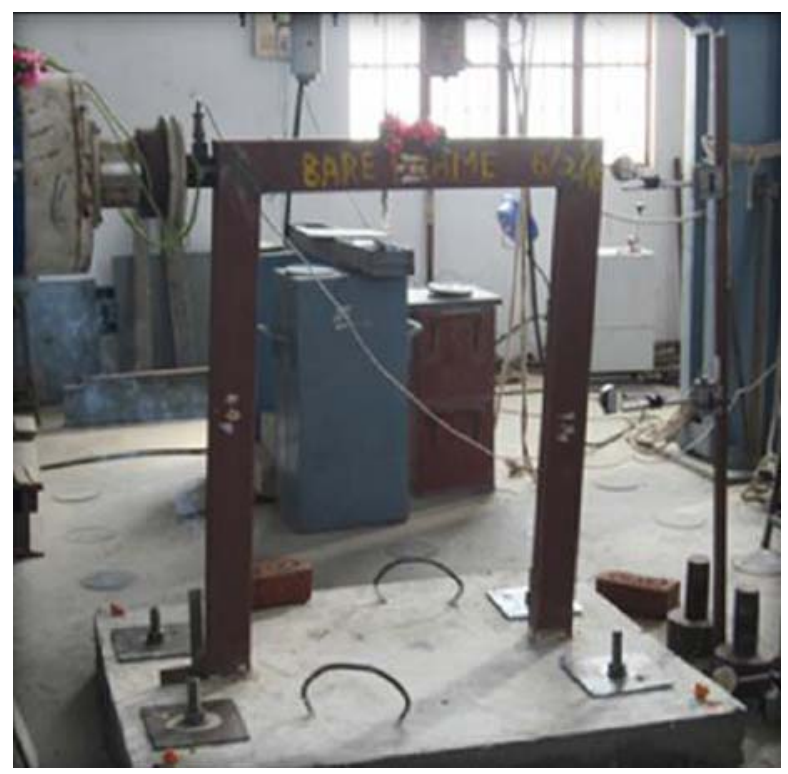

Fig. (1) Geometrical characteristics of experimental model of Eswaramoorthi et. al. [14]. 


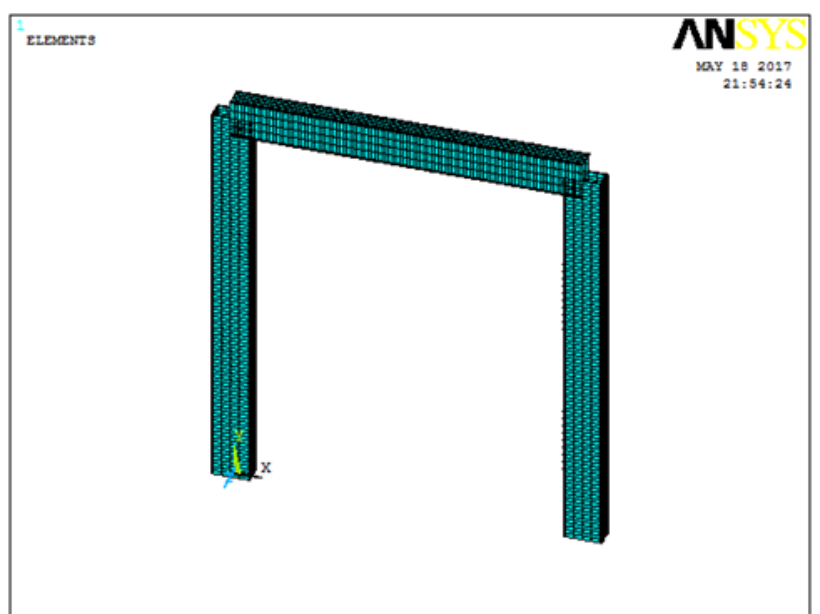

Fig. (2) Shows the generated numerical model

Fig. (1) Represents the experimental sample and fig. (2) Shows the generated numerical model. Fig. (3) Compares force-displacement curves of experimental samples. Fig. (4) Presents stress contours of numerical model.

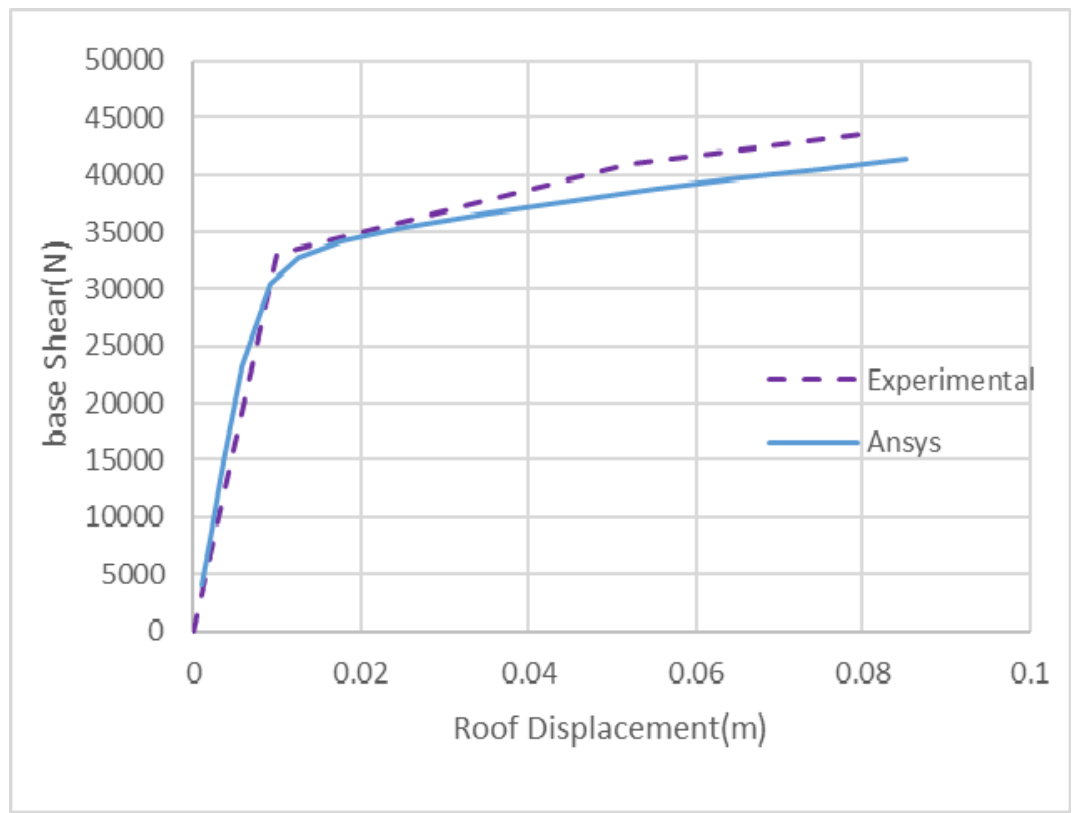

Fig. (3) Comparison between the experimental and finite element models' results 


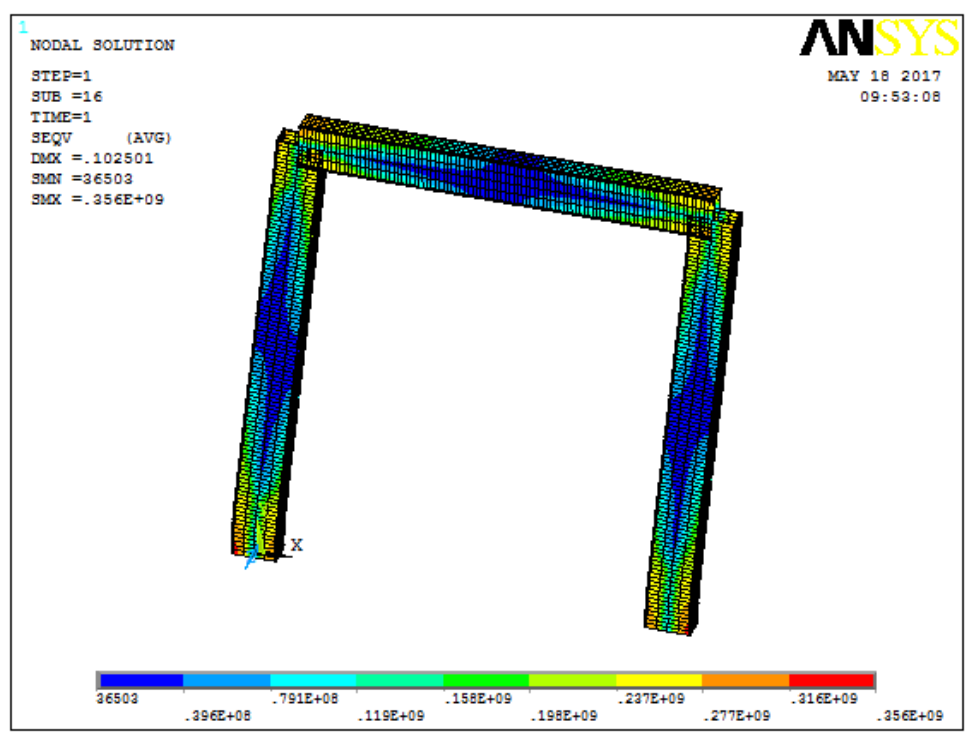

Fig. (4) Stress contour in numerical sample

\section{3-2- Studied models}

Through out this section, the studied models are introducted considering the modelling reliability. In order to study the performance of 3 different types of structures with different dimemsions are utilized. First of all, the structures are designed considering 10th topic of national building regulations code. To study the results betterly, the models are devided in 3 classes considering their story numbers. ADAS damper is assumed to be a four-bladed one and its stiffness is calculated using structure analysis methods. Then the effect of ADAS damper is studied, implementing a composite element in ANSYS software. Tables (2) and (3) represent the characteristics of studied models of this research. The dimensions used in present paper are Meters (m) and Newton (N) for length and force, respectively.

Table (2) Characteristics of studied models

\begin{tabular}{|c|c|c|c|}
\hline Model name & Story number & Span number & Structure type \\
\hline Structure 1 & 5 & 3 & Steel structure \\
\hline Structure 2 & 10 & 3 & Steel structure \\
\hline Structure 3 & 15 & 3 & Steel structure \\
\hline Structure 4 & 5 & 3 & Steel structure with ADAS damper \\
\hline Structure 5 & 10 & 3 & Steel structure with ADAS damper \\
\hline Structure 6 & 15 & 3 & Steel structure with ADAS damper \\
\hline
\end{tabular}

Table (3) the values of gravitational loads

\begin{tabular}{|c|c|}
\hline Load type & Load value \\
\hline Dead & $750 \mathrm{~kg} / \mathrm{m} 2$ \\
\hline Live & $200 \mathrm{~kg} / \mathrm{m} 2$ \\
\hline
\end{tabular}

Fig. (5) Represents the studied models without damper including 5, 10 and 15-story structures. The models with dampers are shown in fig. (6). 


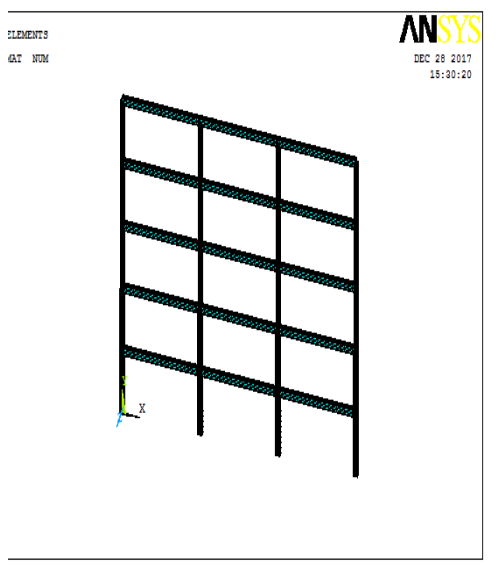

(a) Modelling 5-story structure in ANSYS

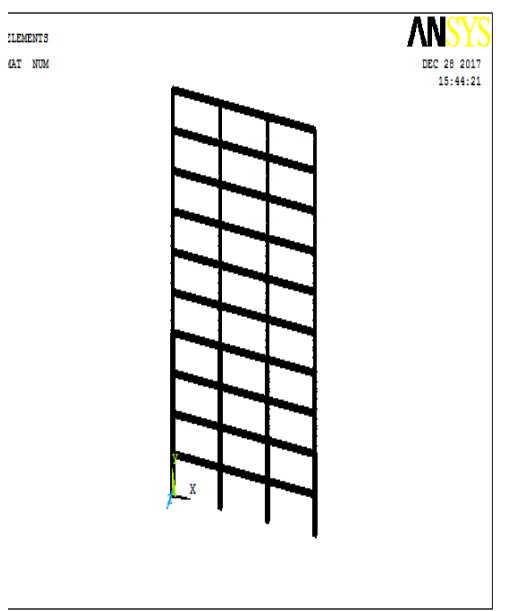

(b) Modelling 10-story structure in ANSYS

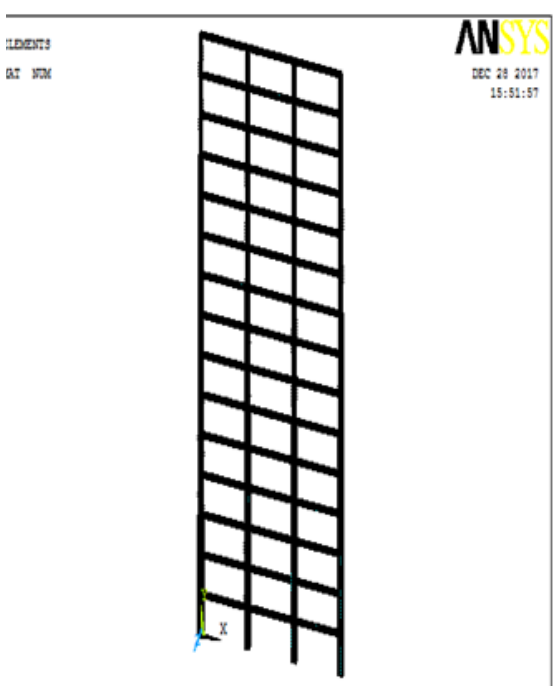

(c) Modelling 15-story structure in
ANSYS

Fig. (5) Studied models without damper
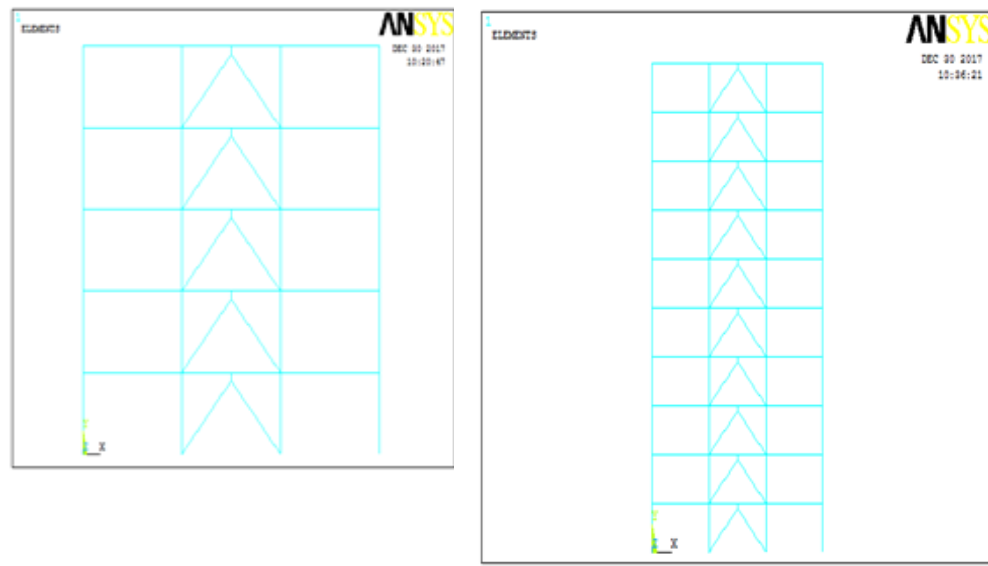

(a) Modelling 5-story structure with ADAS damper in ANSYS

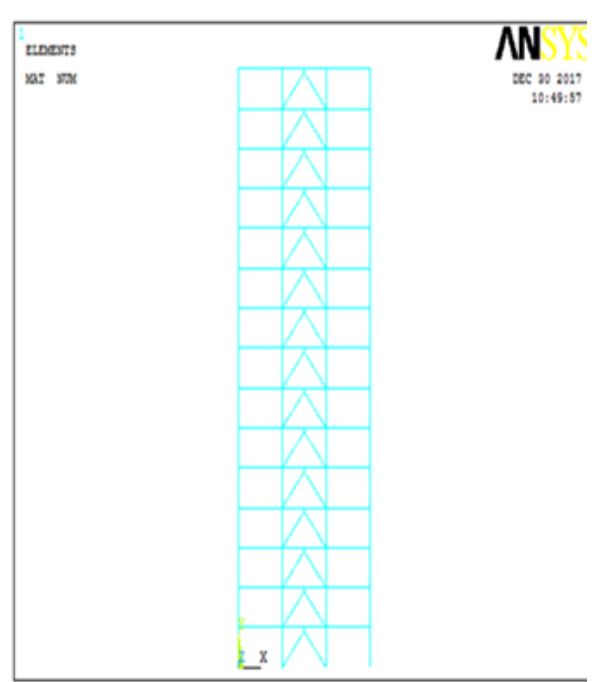

(c) Modelling 15-story structure with ADAS damper in ANSYS (b) Modelling 10-story structure with ADAS damper in ANSYS 
Table (4) Seismic parameters for 6 studied models

\begin{tabular}{|c|c|c|c|}
\hline Model & $\begin{array}{c}\text { Energy absorption } \\
\text { (ton.m) }\end{array}$ & Ductility & $\begin{array}{c}\text { Total strength } \\
\text { (ton) }\end{array}$ \\
\hline STRUCTURE 1 & 151.3 & 3.12 & 632 \\
\hline STRUCTURE 2 & 382.1 & 4.68 & 773 \\
\hline STRUCTURE 3 & 1166 & 4.86 & 2068 \\
\hline STRUCTURE 4 & 399 & 4.9 & 1668 \\
\hline STRUCTURE 5 & 782 & 5.85 & 1880 \\
\hline STRUCTURE 6 & 1642 & 6.03 & 2913 \\
\hline
\end{tabular}

Fig. (7) shows the force-displacement curves for 6 models of 5, 10 and 15-story structures with or without damper.

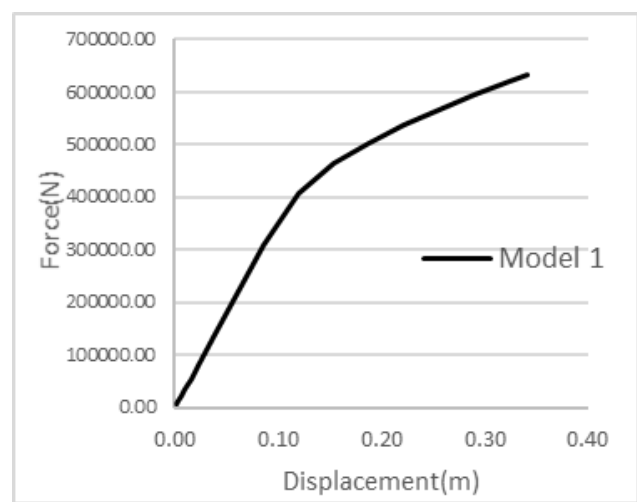

(a) Force-Displacement diagram of model 1

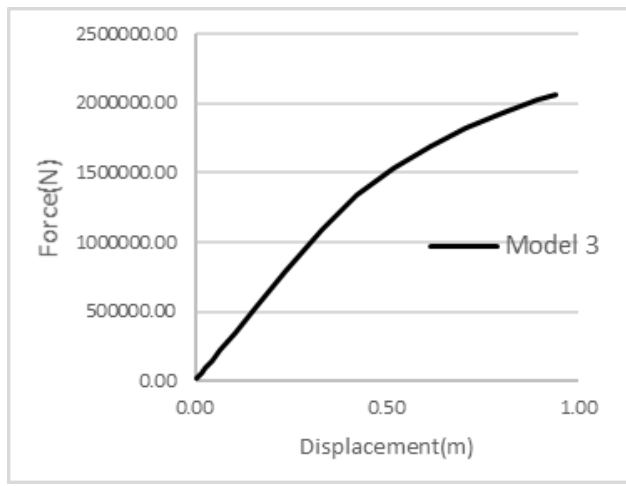

(c) Force-Displacement diagram of model 3

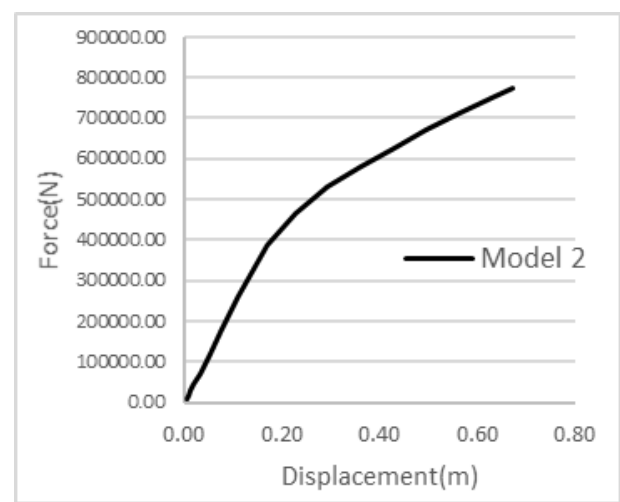

(b) Force-Displacement diagram of model 2

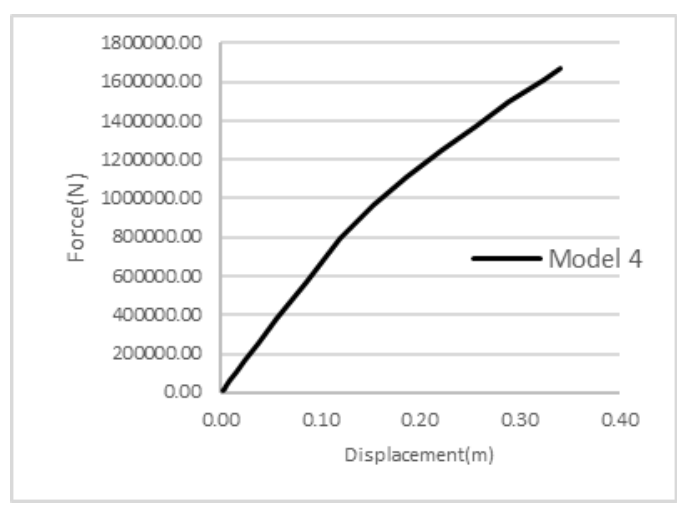

(d) Force-Displacement diagram of model 4 


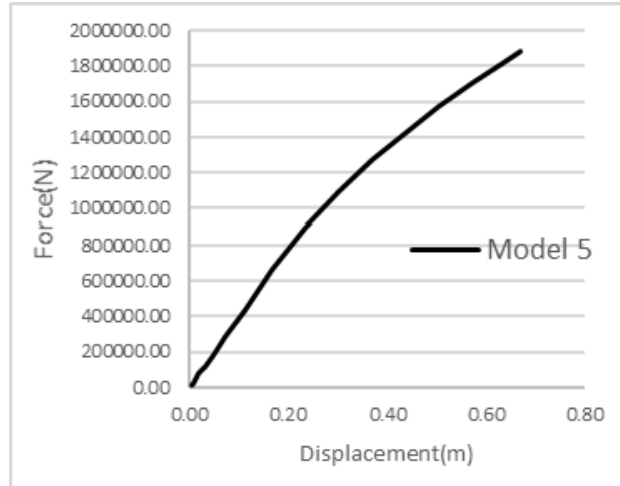

(e) Force-Displacement diagram of model 5

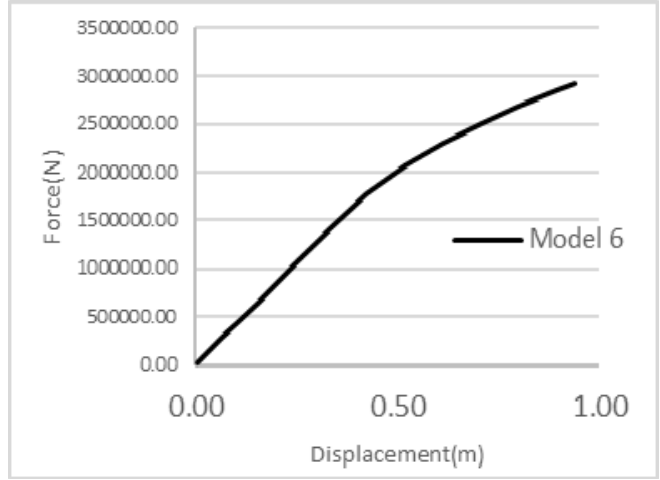

(f) Force-Displacement diagram of model 6

Fig. (7) Load-displacement curves of different models

Displacement is then studied in the models. Fig. (8) shows the displacement of 5-story structure. The displacement of the 10-story structure with out damper is represented in fig. (9).

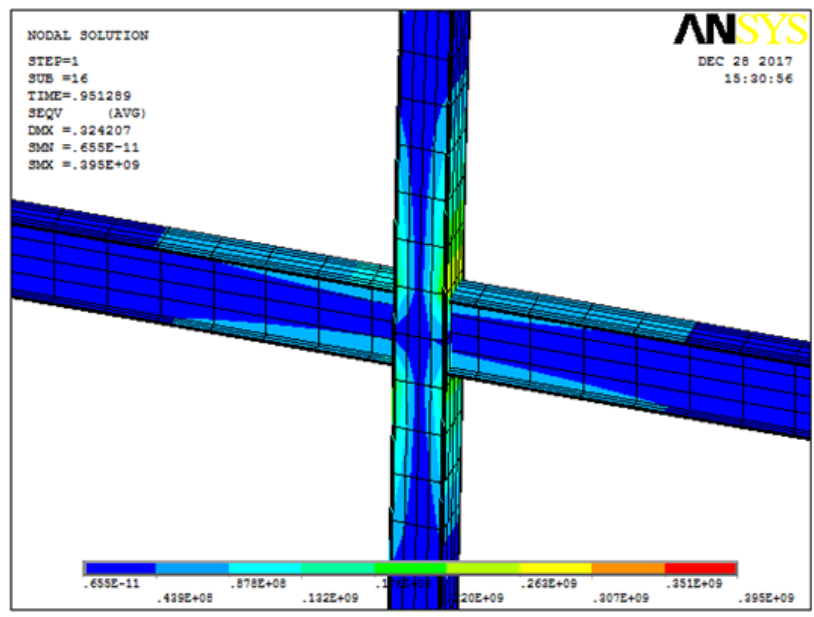

(a) Maximized view of displacement in the first model

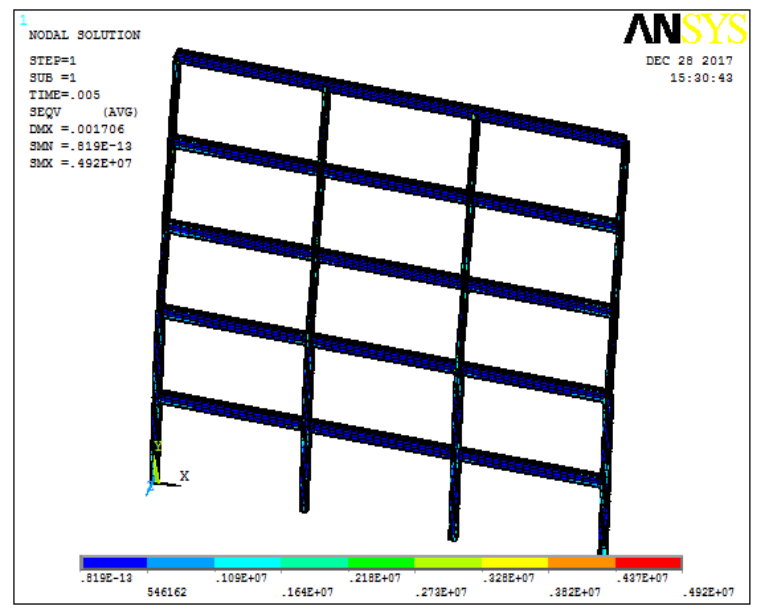

(b) Initiation and joint generation mechanism in the first model

Fig. (8) Displacement of the 5-story structure model without damper

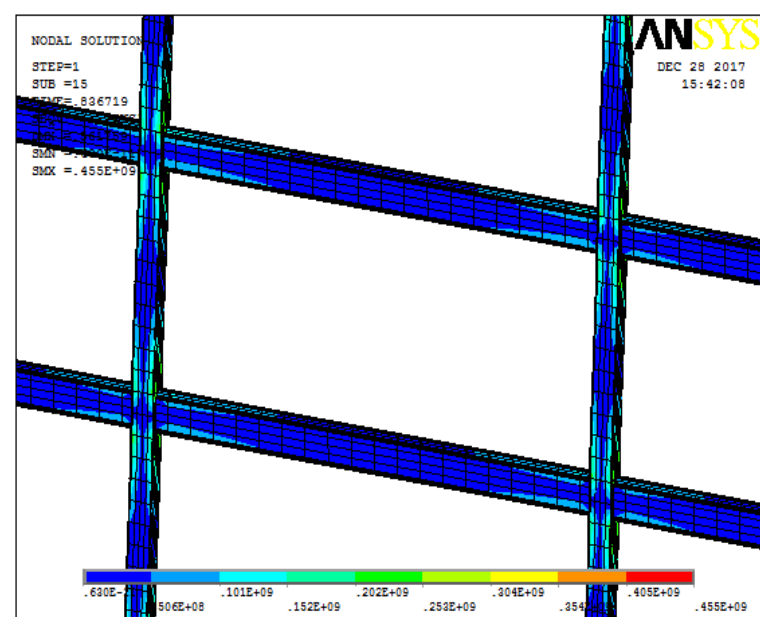

(a) Maximized view of displacement in the second model

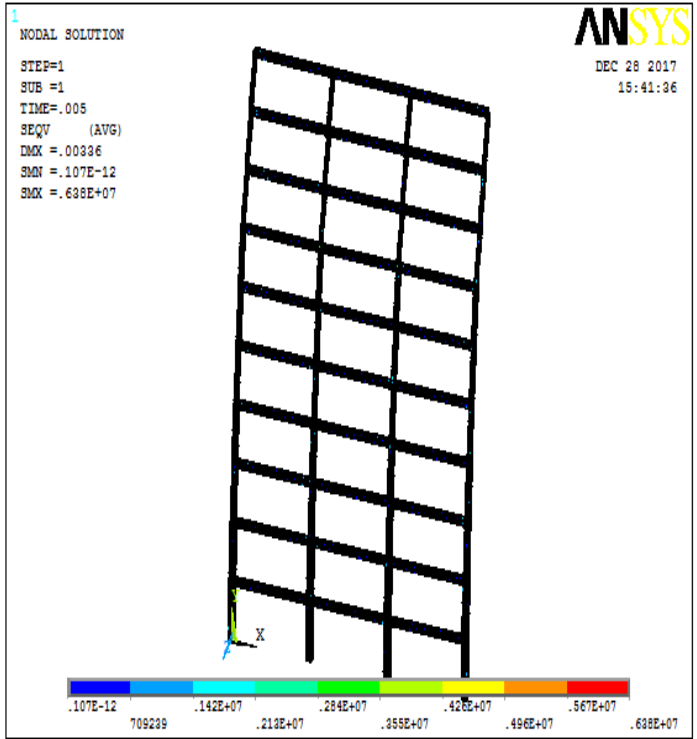

(b) Initiation and joint generation mechanism in the second model

Fig. (9) Displacement of the 10-story structure with ADAS damper 


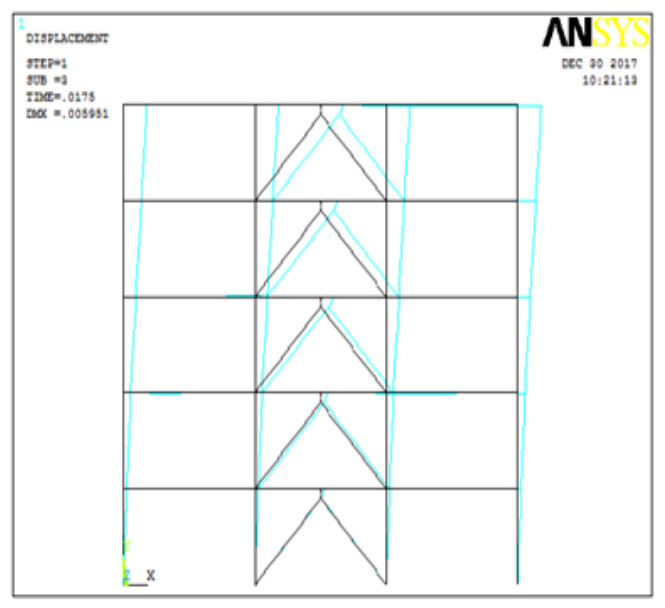

(a) Maximized view of displacement in the first model

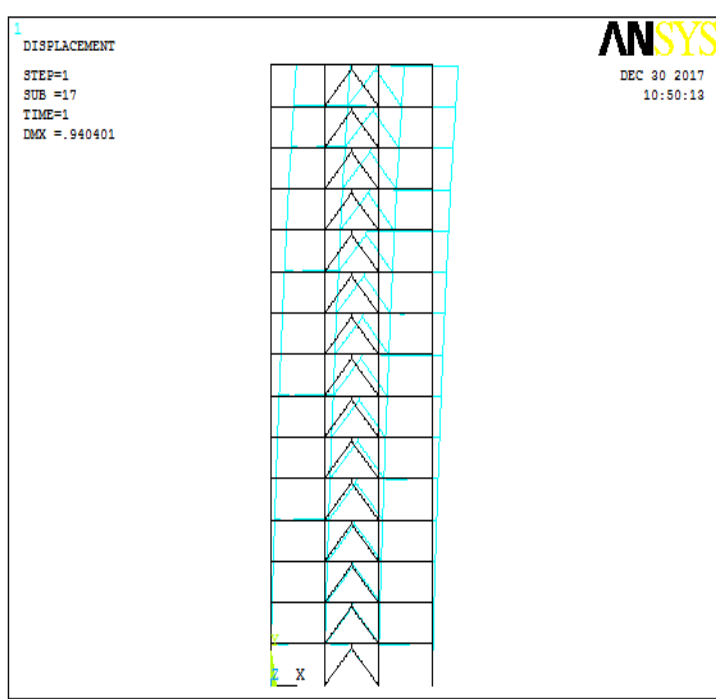

(b) Initiation and joint generation mechanism in the first model

Fig. (10) shows the displacement in the 15-story structure with ADAS damper

\section{4-1- Comparison of structures' seismic parameters}

Bar graphs of total strength for 5, 10 and 15-story structures with and without damper are presented. Considering graph (1)-(a) it is observed that existance of ADAS damper, significantly affects total strength of the system in 5-story structure in such a way that ADAS damper increases the total strength upto 3 times. Thus, the ADAS damper highly improves total strength. Addition of ADAS damper to 10-story structure increases the total strength $143 \%$. Addition of ADAS damper to 15 -story structure increases ductility $24 \%$.

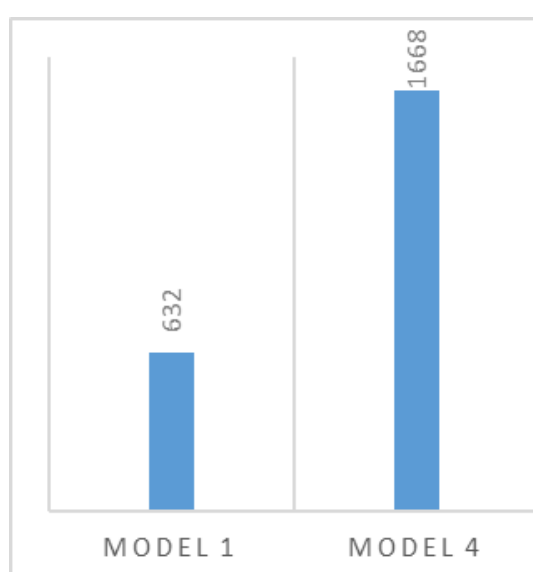

(a) 5-story structure model with and without damper

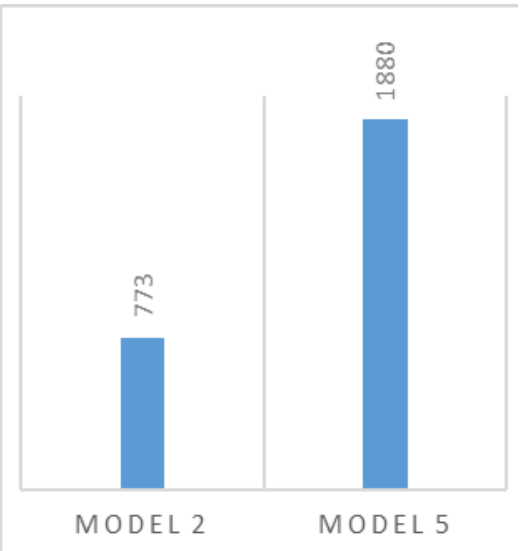

(b) 10-story structure model with and without damper

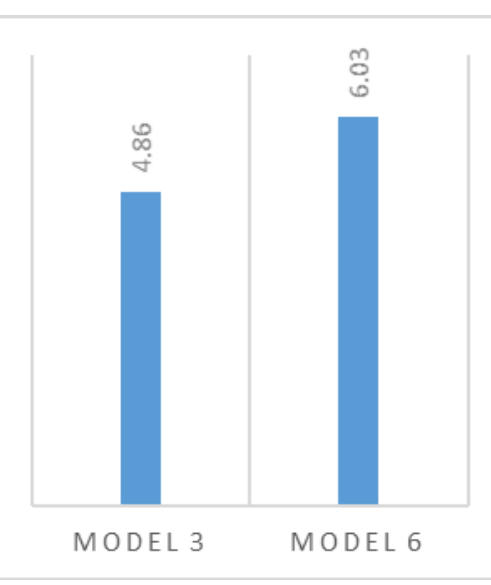

(c) 15-story structure model with and without damper

Graph (1) Comparative bar graph of total strength in studied models

\section{4-2- Ductility comparison}

Considering graph (2), ADAS damper has a significant effect on ductility of system. As it is obvious, ductility is increased $57 \%$ by adding ADAS damper. Using ADAS damper has increased ductility $25 \%$ in the 10 -story structure. In the 15 -story structure, ductility has been increased $11 \%$ by addition of ADAS damper. 


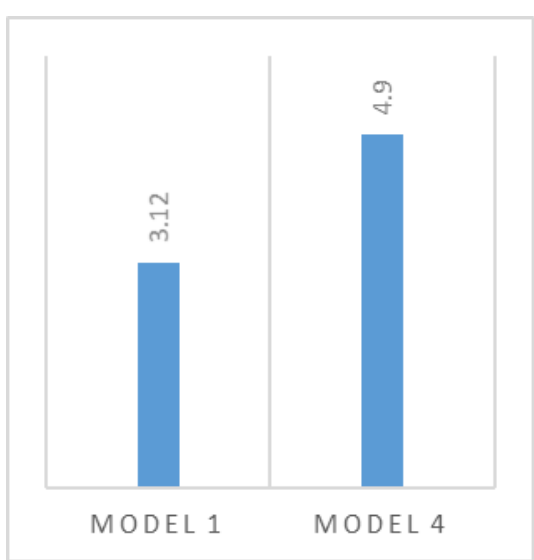

(a) 5-story structure model with and without damper

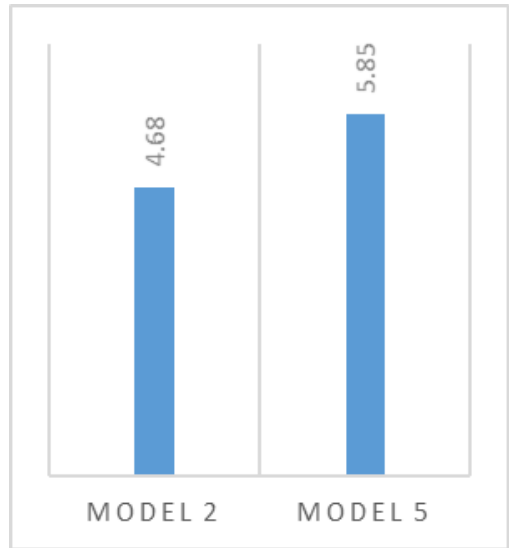

(b) 10-story structure model with and without damper

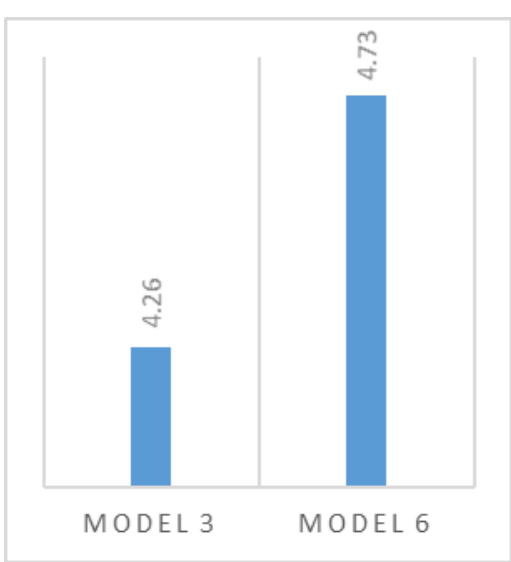

(c) 15-story structure model with and without damper

Graph (2) Comparative bar graph of total strength in studied models

\section{4-3- Comparison of energy absorption}

Addition of ADAS damper increases energy absorption 164\% in 5-story structure. It increases the energy absorption in 10 -story structure $104 \%$. In 15 -story structure, energy absorption increased $40 \%$, by adding ADAS damper. Energy absorption increment is more significant in short structures.

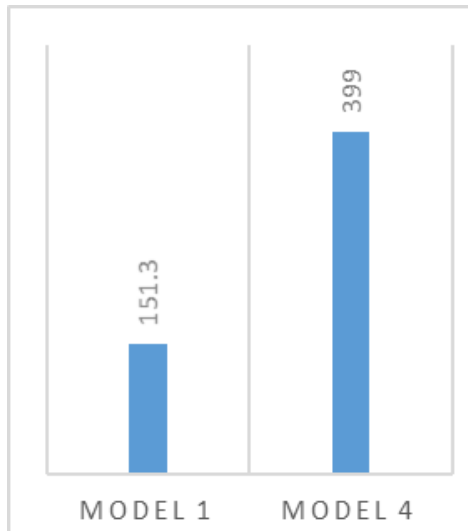

(a) 5-story structure model with and without damper

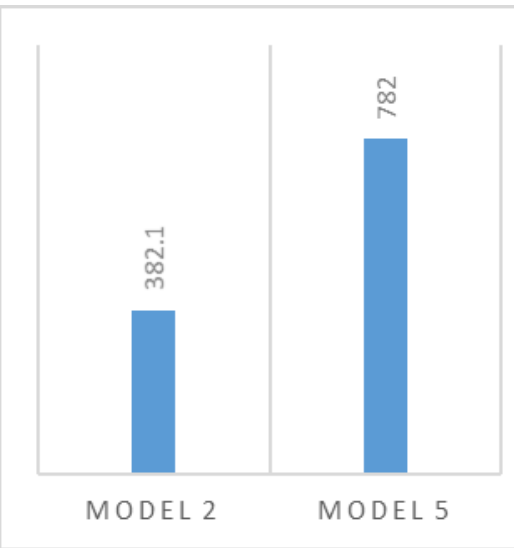

(b) 10-story structure model with and without damper

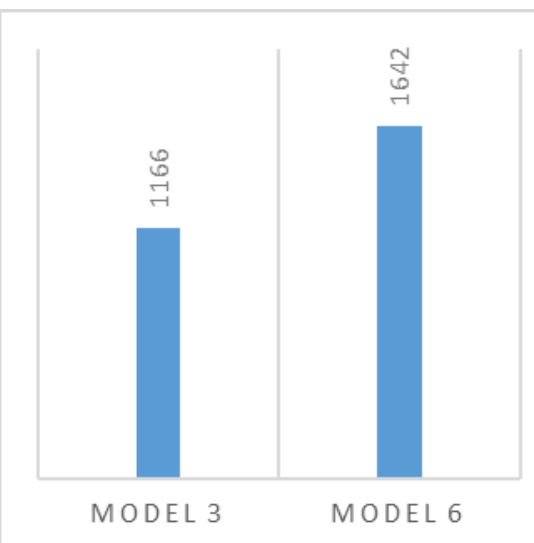

(c) 15 -story structure model with and without damper

Graph (3) Comparative bar graph of total strength in studied models

\section{Discussion and conclusion}

Through this paper, latteral seismic bearing behavior of steel structures with and without ADAS damper is studied and compared. Summary of conclusions are presented here:

- In short height structures (5-story)

- ADAS damper system increases total strength 3 times.

- ADAS damper system increases ductility $57 \%$.

- ADAS dmaper system increases energy absorption $164 \%$.

- In moderate height structures (10-story)

- ADAS damper system increases total strength $143 \%$.

- ADAS damper system increases ductility $25 \%$.

- ADAS dmaper system increases energy absorption 104\%.

- In tall structures (15-story)

- ADAS damper system increases total strength $24 \%$.

- ADAS damper system increases ductility $11 \%$.

- ADAS dmaper system increases energy absorption $40 \%$. 


\section{Reference:}

[1] Elghazouli AY. (2010). Assesment of European seismic design procedures for steel framed structure. Bull Earth Eng 8:65-89.

[2] Mastrandreal I, Piluso V. (2009). Plastic design of eccentrically braced frames. J constr Steel Res; 65 (5):1015-28.

[3] Gul Yigitsoy, Cem Tokaya, Taichiro Okazaki. (2014). Stability of Beams in steel eccentrically braced frames. journal of Constructional steel research, 96-14-25.

[4] Yigitsoy G, 2010, A numerical Study on beam stability in eccentrically braced frames, Ankara, turkey: middle East Technical University.

[5] Soong TT, Dargush GF. Passive energy dissipation systems in structural engineering. Chichester (England): John Wiley \& Sons; 1997.

[6] IRANIAN CODE OF PRACTICE FOR SIESMIC RESISTANCE DESIGN OF BUILDING. Standard No.2800.(4 Edition).

[7] Christopoulos C, Filiatrault A. Principles of passive supplemental damping and seismic isolation. Pavia (Italy): IUSS Press; 2006.

[8] Symans MD, Charney FA, Whittaker AS, Constantinou MC, Kircher CA, Johnson MW, et al. Energy dissipation systems for seismic applications: current practice and recent developments. ASCE J Struct Eng 2008;134(1):3-21.

[9] Soong TT, Spencer Jr BF. Supplemental energy dissipation: state-of-the-art and state-of-the practice. Eng Struct 2002;24:243-59.

[10] Rai DC, Annam PK, Pradhan T, Seismic testing of steel braced frames with aluminum shear yielding dampers. Engineering Structures 2013;46:737-747.

[11] Deng K, Pan P, Sun J, Liu J, Xue Y. Shape optimization design of steel shear panel dampers. J Constr Steel Res 2014;99:187-93

[12] Li HN, Li G, Experimental study of structure with "dual function" metallic dampers. Engineering Structures 2007;29:1917-1928.

[13] Ricky WKC, Albermania F, Experimental study of steel slit damper for passive energy dissipation. Engineering Structures 2008;30 :1058-1066.

[14] Dinesh, P. Eswaramoorthi1 P. Magudeaswaran2 A. "PUSHOVER ANALYSIS OF STEEL FRAME." Int J Adv Engg Tech/Vol. VII/Issue II/April-June 1061 (2016): 1062. 